\title{
Hypomethylation of LINE-1 and Alu in well-differentiated neuroendocrine tumors (pancreatic endocrine tumors and carcinoid tumors)
}

\author{
In-Seon Choi ${ }^{1}$, Marcos RH Estecio ${ }^{2}$, Yasuhiko Nagano ${ }^{1}$, Do Ha Kim ${ }^{1}$, Jill A White ${ }^{1}$, \\ James C Yao ${ }^{3}$, Jean-Pierre J Issa ${ }^{2}$ and Asif Rashid ${ }^{1}$ \\ ${ }^{1}$ Department of Pathology, The University of Texas MD Anderson Cancer Center, Houston, TX, USA; \\ ${ }^{2}$ Department of Leukemia, The University of Texas MD Anderson Cancer Center, Houston, TX, USA and \\ ${ }^{3}$ Department of Gastrointestinal Medical Oncology, The University of Texas MD Anderson Cancer Center, \\ Houston, TX, USA
}

\begin{abstract}
Neuroendocrine tumors including carcinoid tumors and pancreatic endocrine tumors are uncommon, and the genetic alterations in these indolent tumors are not well characterized. We studied global hypomethylation by analyzing long interspersed nucleotide elements (LINE)-1 and Alu methylation using pyrosequencing in 35 neuroendocrine tumors and corresponding normal tissue. The tumor samples were less methylated than normal tissue at LINE-1 $(P=0.04)$ and Alu $(P=0.001)$. The mean relative tumor hypomethylation (difference in methylation between normal tissue and in tumor) was $11.5 \pm 10.0$ for LINE-1 and $5.8 \pm 6.4$ for Alu, and were correlated with each other (correlation coefficient $0.6, P=0.001$ ). Relative tumor hypomethylation of LINE-1 was higher in ileal carcinoid tumors than in non-ileal carcinoid tumors and pancreatic endocrine tumors $(P=0.047)$, and tumors with lymph node metastasis $(P=0.02)$, chromosome 18 loss $(P=0.001)$ and $R A S$-association domain family 1 , isoform $A$ gene methylation $(P=0.02)$. Alu methylation in tumors was inversely correlated with methylation of $O^{6}$-methyl-guanine methyltransferase gene $(P=0.02)$. Our study shows that hypomethylation is more common in carcinoid tumors than in pancreatic endocrine tumors and is associated with clinicopathologic features, and genetic and epigenetic alterations in these tumors, including lymph node metastasis. Modern Pathology (2007) 20, 802-810; doi:10.1038/modpathol.3800825; published online 4 May 2007
\end{abstract}

Keywords: pancreatic endocrine tumors; carcinoid tumors; hypomethylation; LINE; Alu

Neuroendocrine tumors, including pancreatic endocrine tumors and carcinoid tumors, are uncommon, mostly well-differentiated and indolent neuroendocrine neoplasms, with an age-adjusted annual incidence of $<1$ per $100000 .^{1,2}$ The molecular mechanisms of neuroendocrine tumors are poorly understood but have been the focus of many recent reports. ${ }^{3-10}$

The methylation of cytosine in CpG dinucleotides is an important epigenetic modification of DNA in the vertebrate genome. ${ }^{11}$ Methylation of cytosines and other associated epigenetic modifications is associated with transcriptional silencing of about

Correspondence: Dr A Rashid, MD, PhD, Department of Pathology, The University of Texas, MD Anderson Cancer Center, 1515 Holcombe Boulevard, Box 85, Houston, TX 77030-4095, USA.

E-mail: arashid@mdanderson.org

Received 02 March 2007; revised 05 April 2007; accepted 09 April 2007; published online 4 May 2007 one-half of the human genes with abundant CpG dinucleotides (CpG islands) in the promoter region, and is important in development and aging. ${ }^{12-14}$ Carcinogenesis is associated with changes in this epigenetic phenomenon, including two distinct and seemingly opposing trends: global decrease in cytosine methylation (hypomethylation) and methylation of cytosine in CpG islands (hypermethylation). ${ }^{12-14}$ Global hypomethylation of cytosine residues in the DNA has been reported in a diverse group of tumors. ${ }^{15-17}$ Long interspersed nucleotide elements (LINE) are 6-8 kb long, GC-poor sequences encoding an RNA-binding protein and a reverse transcriptase/endonuclease making up $15 \%$ of human genome with half a million copies, and LINE-1 are the most abundant. ${ }^{18,19}$ Alu-repetitive elements are shorter, $\sim 300 \mathrm{bp}$ in length, GC-rich, derived from 7SL RNA, and make up 10\% of human genome with $\sim 1.4$ million copies. ${ }^{20,21}$ The LINE-1 and Alu elements are heavily methylated, and it is estimated 
that more than a third of DNA methylation occurs in the repetitive sequences. ${ }^{21,22}$ Bisulfite treatment of DNA, followed by a PCR reaction that amplifies a pool of Alu or LINE-1-repetitive elements, can be used as a surrogate marker for genome-wide DNA methylation changes. ${ }^{23}$

Pancreatic endocrine tumors and carcinoid tumors share some clinicopathologic features and molecular alterations, including neuroendocrine differentiation. Some tumors produce endocrine activity causing a clinical syndrome, variable growth patterns and behavior and involvement of multiple endocrine neoplasia type 1 gene, but have site-specific differences in other genetic and epigenetic alterations. ${ }^{3-10}$ We studied methylation of LINE-1 and Alu in low-grade neuroendocrine tumors and corresponding normal tissue from the same patients, and compared methylation densities of tumor, normal tissue and relative tumor hypomethylation (difference in methylation between normal and tumor) with clinicopathologic features.

\section{Materials and methods}

Characteristics of Cell Lines, Specimens and Patients

RKO and SW48 colon cancer cell lines, as well as H322 lung cancer cell line and MB435 breast cancer cell lines (American Type Culture Collection, Manassas, VA, USA), were grown in recommended culture medium, and genomic DNA was extracted. Frozen tumor and corresponding normal mucosa or non-neoplastic pancreatic parenchyma of previously characterized 35 patients, ${ }^{7,9,10}$ who underwent resection for a neuroendocrine tumor, were obtained from surgical specimens in the frozen section laboratory of the Department of Pathology at the MD Anderson Cancer Center. The Surveillance Committee (institutional review board) approved this study. The patient records and histopathological findings were reviewed. The tumors were classified as neuroendocrine tumors using established criteria, as reported previously. ${ }^{24}$ The functional status of each tumor was ascertained by serum measurements of hormones and/or clinical syndrome due to hormonal production.

\section{DNA Extraction and Bisulfite Treatment}

DNA from both tumor and non-neoplastic tissue in microdissected fresh-frozen specimens was extracted using a commercial kit (Qiagen DNA extraction kit, Qiagen Inc., Valencia, CA, USA), after a hematoxylin and eosin-stained slide from a frozen block was reviewed. The tumor cell cellularity was at least $70 \%$ in all samples. All the tumor and nonneoplastic tissue was obtained from the primary tumor and surrounding non-neoplastic mucosa, pancreas or lung parenchyma.
DNA was treated with bisulfite, which selectively deaminates cytosine but not 5-methylcytosine to uracil. In brief, $2.0 \mu \mathrm{g}$ of DNA was denatured in $5.5 \mu \mathrm{l}$ of $0.2 \mathrm{M} \mathrm{NaOH}$ for $10 \mathrm{~min}$ at $37^{\circ} \mathrm{C}$ followed by incubation with $30 \mu \mathrm{l}$ of freshly prepared $10 \mathrm{mM}$ hydroquinone (Sigma-Aldrich, St Louis, MO, USA), and $520 \mu \mathrm{l}$ of $3 \mathrm{M}$ sodium bisulfite (Sigma-Aldrich) at pH 5.0 were added and mixed. The samples were overlaid with mineral oil to prevent evaporation and incubated at $50^{\circ} \mathrm{C}$ for $16 \mathrm{~h}$. Bisulfite-treated DNA was isolated using the Wizard DNA Clean-Up System (Promega, Madison, WI, USA). DNA was eluted by $50 \mu \mathrm{l}$ of warm water, and $5.5 \mu \mathrm{l}$ of $3 \mathrm{M}$ $\mathrm{NaOH}$ was added for $5 \mathrm{~min}$. DNA was ethanol precipitated with glycogen as a carrier and resuspended in $100 \mu \mathrm{l}$ water. Bisulfite-treated DNA was stored at $-20^{\circ} \mathrm{C}$.

\section{Quantitation of LINE-1 and Alu Methylation}

The LINE-1 and Alu methylation was quantitated by pyrosequencing using the primers and conditions as described previously. ${ }^{23}$ LINE-1 assay was performed using 10 pmol of forward primer 5'-TTTTGAGTT AGGTGTGGG-3' and 10 pmol of reverse biotinylated primer 5'-TCTCACTAAAAAATACCAAACAA-3'. Alu assay was performed using 10 pmol of forward primer 5'-GGGACACCGCTGATCGTATATTTTTATT AAAAATATAAAAATTAGT-3', 10 pmol of reverse primer 5'-CCAAACTAAAATACAATAA-3' and 10 pmol of biotinylated primer $5^{\prime}$-GGGACACCGCTG ATCGTATA-3'. The LINE-1 and Alu assays were performed in a $50 \mu \mathrm{l}$ PCR reaction containing $50 \mathrm{ng}$ of bisulfite-treated genomic DNA, $60 \mathrm{mM}$ Tris- $\mathrm{HCl}$, $\mathrm{pH}$ 8.8, $15 \mathrm{mM}$ ammonium sulfate, $0.5 \mathrm{mM} \mathrm{MgCl}_{2}$, $1 \mathrm{mM}$ dNTP mix and $1 \mathrm{U}$ of Taq polymerase. PCR cycling conditions were $95^{\circ} \mathrm{C}$ for $30 \mathrm{~s}, 47^{\circ} \mathrm{C}$ for $30 \mathrm{~s}$ and $72^{\circ} \mathrm{C}$ for $30 \mathrm{~s}$ for 47 cycles. The PCR product was purified and quantitated using the PSQ HS 96 Pyrosequencing System (Pyrosequencing Inc., Westborough, MA, USA). The ratio of $\mathrm{C}$ to $\mathrm{T}$ nucleotides was evaluated for LINE-1 methylation, and ratio of two $G$ to $A$ nucleotides were evaluated for $\mathrm{Alu}$ methylation (examples in Figure 1). DNA from RKO, SW48, H322 and MB435 cell lines were used as controls for optimizing the assay. DNA from SssI treated DNA was used as positive control and deionized water as negative controls, respectively. The experiments were repeated twice and mean values were taken from these separate experiments.

The mean LINE-1 methylation in SssI-treated normal samples, including placental DNA and normal samples from patients, was $91.7 \pm 1.0 \%$, and mean Alu methylation was $28.8 \pm 1.2 \%$. All subsequent values were represented by multiplying the sample value by 100 and dividing by mean methylation level of SssI-treated normal DNA. LINE1 and Alu relative tumor hypomethylation were calculated by subtracting LINE-1 and Alu methylation levels of normal sample from the LINE-1 and 

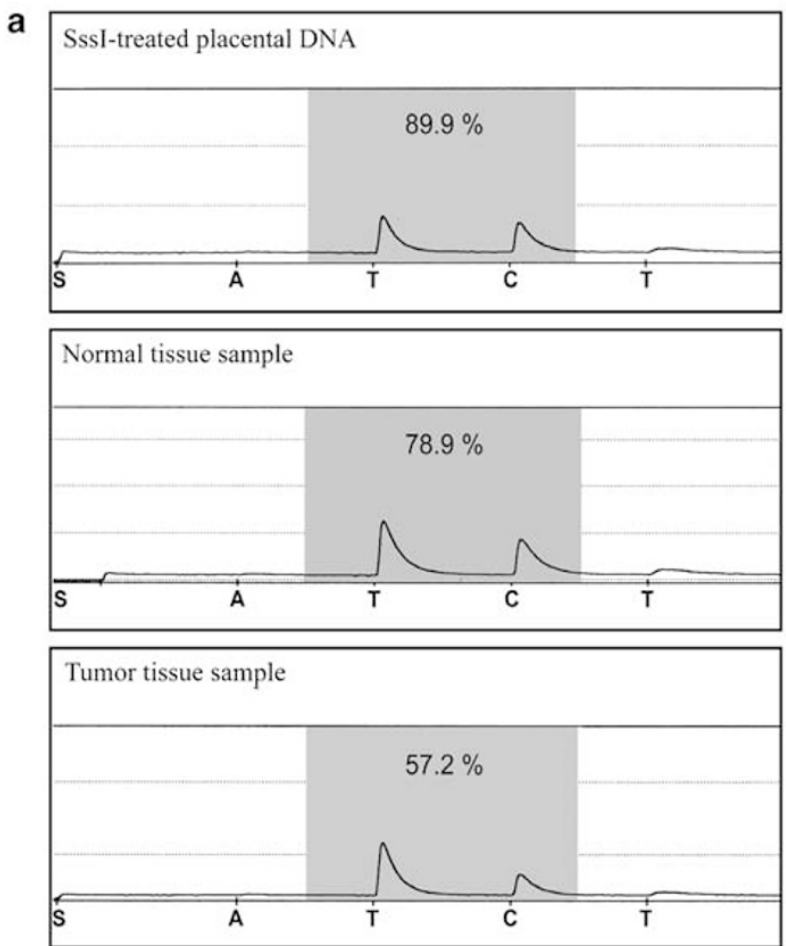
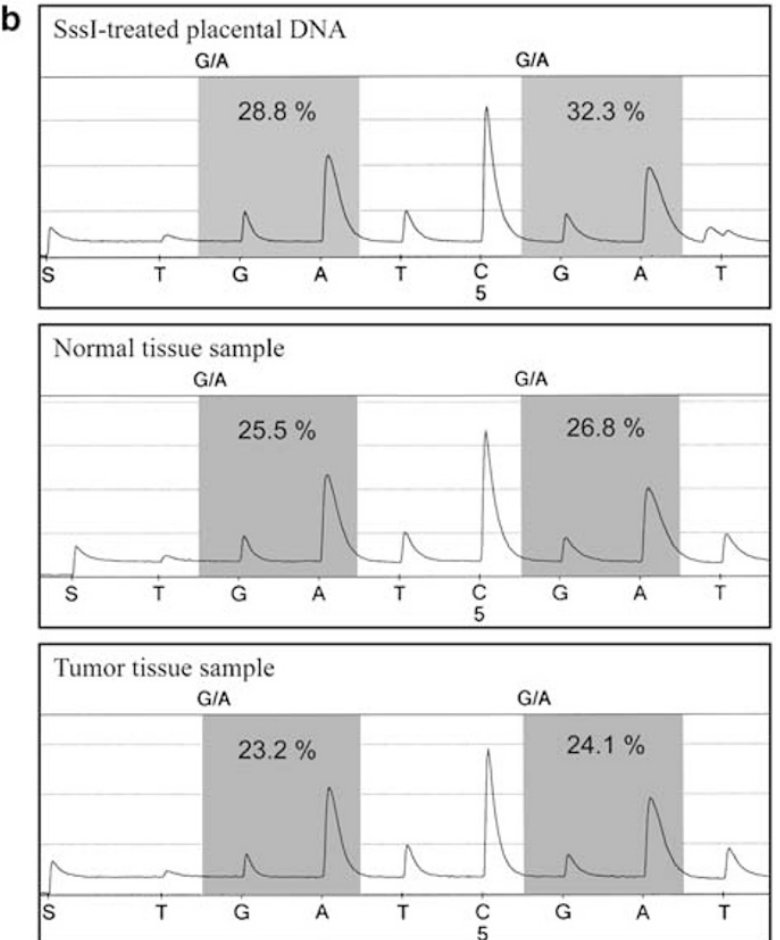

Figure 1 Quantification of LINE-1 (a) and Alu (b) methylation by pyrosequencing of bisulfite-treated DNA samples. The top samples show methylation of SssI methylase-treated placental DNA, the middle panels of a normal tissue sample and the lower panels of the corresponding tumor samples. The PCR product was purified and methylation was quantified using the PSQ HS 96 Pyrosequencing System (Pyrosequencing Inc.). The program quantifies $\mathrm{C}$ or $\mathrm{G}$ nucleotides for methylated and A or T for unmethylated or mutated sequences. The shaded regions represent one CpG site in LINE-1 and two CpG sites in Alu elements used for quantification of methylation at each site, and the percent methylation at each site is shown above the peaks. The maximum absolute methylation was calculated by SssI-treated samples of placental DNA and normal tissue.

Alu methylation levels of corresponding tumor sample, respectively.

\section{Genetic and Epigenetic Alterations in Neuroendocrine Tumors}

The genetic and epigenetic alterations in these 35 tumors have been reported previously. ${ }^{9,10}$ Chromosome $11 \mathrm{q}$ loss was present in seven $(20 \%)$, chromosome $16 q$ loss in six $(17 \%)$ and chromosome 18 loss in $11(31 \%)$ tumors; methylation of $p 14$ gene was present in 20 tumors $(57 \%)$, $p 16$ gene in nine $(26 \%)$, $O^{6}$-methyl-guanine methyltransferase (MGMT) gene in three ( $9 \%)$ and $R A S$-association domain family 1 , isoform $A(R A S S F 1 A)$ gene in $19(54 \%)$ tumors.

\section{Statistical Analysis}

All statistical analysis was performed using SPSS (SPSS Inc., Chicago, IL, USA). Comparisons of categorical variables were made using $\chi^{2}$ test and Fisher's exact test. Comparison of methylation density and clinicopathologic features was evaluated by ANOVA test and Student's $t$-test. Correlations among methylation densities were evaluated by means of Spearman's rank correlation coefficient.

\section{Results}

\section{Clinicopathologic Features}

The genetic and epigenetic alterations and clinicopathologic features of 35 patients with neuroendocrine tumors have been reported previously.,10 Eleven patients had a pancreatic endocrine tumor and 24 had a carcinoid tumor. The primary site of carcinoid tumors was lung for four patients, stomach for two patients, duodenum for one patient, ileum for 15 patients and colon (cecum) for two patients. Two patients had benign neuroendocrine tumors, whereas six had uncertain malignant potential and the remaining 27 had malignant neuroendocrine tumors. Lymph node metastasis was present in 22 patients, and liver metastasis in 15 patients. All but three patients are alive.

\section{LINE-1 and Alu Methylation}

Levels of LINE-1 and Alu methylation in normal and tumor samples are shown in Figure 2. All cell lines were hypomethylated compared to SssI-treated normal samples. RKO, SW48, H322 and MB435 cell lines had LINE-1 methylation levels of 68.4, 63.0, 63.5 and 57.1, respectively, and Alu methylation levels of 70.5, 68.5, 68.1 and 57.1, respectively. 


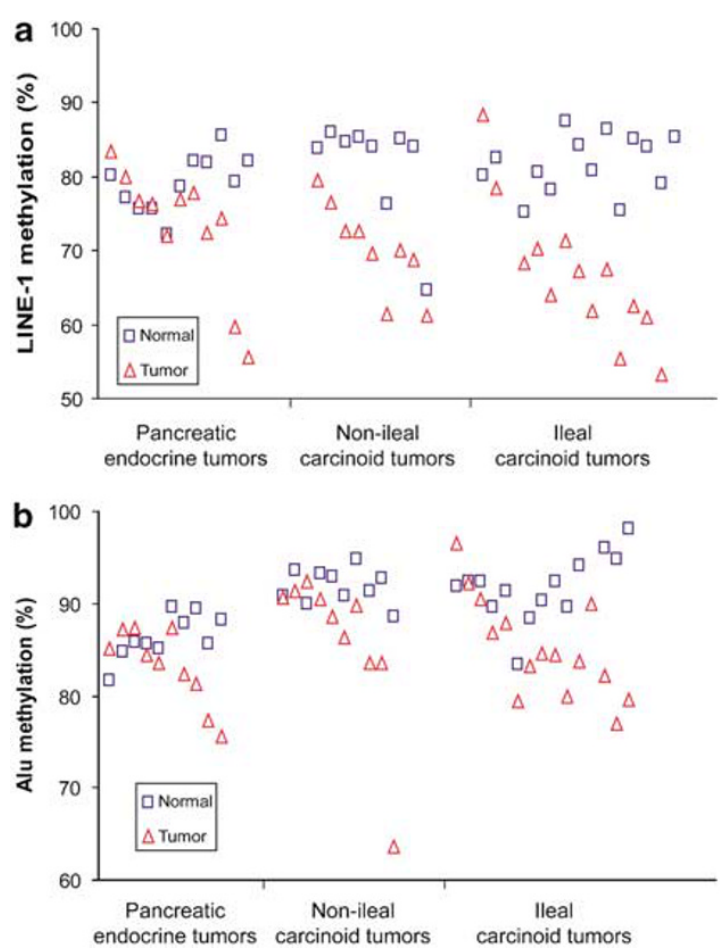

Figure 2 Percent of LINE-1 (a) and Alu (b) methylation in normal tissue and corresponding tumor tissue in samples from 35 patients with neuroendocrine carcinomas represented after dividing by absolute methylation levels in SssI-treated placental and normal tissue samples. The Alu methylation levels in normal pancreatic samples were lower compared with normal tissue from patients with non-ileal and ileal carcinoid tumors $(P=0.001)$, and the tumor samples were less methylated than normal tissue at LINE-1 $(P=0.04)$ and Alu $(P=0.001)$. LINE-1- and Alu relative tumor hypomethylation was calculated by subtracting methylation levels of the normal sample from the methylation levels of the corresponding tumor sample.

The tumor samples were less methylated than normal tissue at LINE-1 and Alu. The mean LINE-1 methylation in tumor samples was $68.5 \pm 10.0$ compared with $80.0 \pm 7.1$ in normal samples $(P=0.04)$ and the mean Alu methylation in tumor samples was $84.9 \pm 6.0$ compared with $90.5 \pm 4.2$ in normal samples $(P=0.001)$. The mean relative tumor hypomethylation was $11.5 \pm 10.0$ for LINE-1 and $5.8 \pm 6.4$ for Alu. Twenty tumors had LINE-1 hypomethylation of $>10 \%$, whereas 10 had hypomethylation of $<10 \%$ and the remaining five tumors had slight relative hypermethylation. Similarly, seven tumors had Alu hypomethylation of $>10 \%$, whereas 24 had hypomethylation of $<10 \%$ and the remaining four tumors had slight relative hypermethylation.

The LINE-1 and Alu methylation in tumor samples were correlated with each other. The LINE-1 tumor methylation levels and Alu tumor methylation levels were correlated (correlation coefficient $0.45, P=0.008$ ) and the LINE-1 relative tumor hypomethylation levels and Alu relative tumor hypomethylation levels were correlated (correlation coefficient 0.6, $P=0.001$, Figure 3).

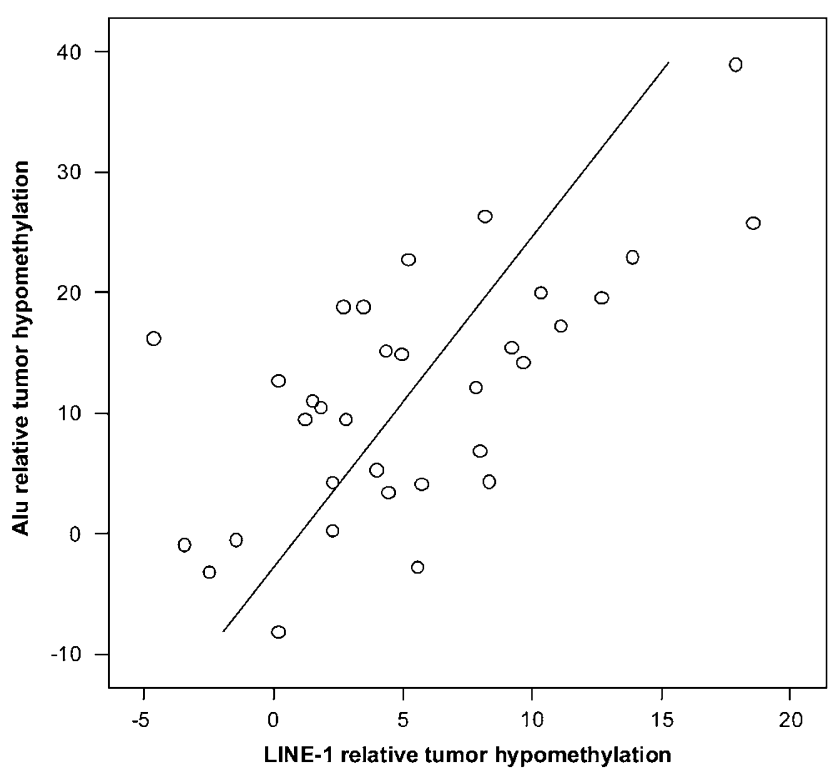

Figure 3 LINE-1 relative tumor hypomethylation (or hypermethylation) and Alu relative tumor hypomethylation (or hypermethylation) are correlated (correlation coefficient $0.6, P=0.001$ ).

In contrast, there was no significant correlation between LINE-1 and Alu methylation levels in normal samples, LINE-1 methylation in tumor and normal samples and Alu methylation in tumor and normal samples.

\section{LINE-1 and Alu Methylation and Clinicopathologic Features}

The Alu methylation levels in normal pancreatic samples were lower $(86.4 \pm 2.4)$ compared with normal tissue from patients with non-ileal $(92.1 \pm 1.9)$ or ileal $(92.4 \pm 4.2)$ tumors $(P=0.001$, Figure 2b). There was no significant association between LINE-1 or Alu methylation levels in normal tissue and other clinicopathologic features including age and gender.

The LINE-1 methylation levels and relative tumor hypomethylation levels were associated with multiple clinicopathologic features, and genetic and epigenetic alterations (Tables 1 and 2). LINE-1 methylation was lower in larger tumors $(P=0.01)$, and in tumors with lymph node metastasis $(P=0.01)$, chromosome 18 loss $(P=0.02)$, and RASSF1A gene methylation $(P=0.03)$. Similarly, relative tumor hypomethylation of LINE-1 was greater (lower methylation levels than in normal tissue) in ileal carcinoid tumors than in non-ileal carcinoid tumors and pancreatic endocrine tumors $(P=0.047)$, and in tumors with lymph node metastasis $(P=0.02)$, chromosome 18 loss $(P=0.001)$ and RASSF1A gene methylation $(P=0.02)$. These associations were also present if tumors were dichotomized into those with $>10 \%$ hypomethylation of 
Table 1 Association of LINE-1 tumor methylation densities and clinicopathologic features

\begin{tabular}{|c|c|c|c|}
\hline Clinicopathologic features (\#) & Number of tumors & Tumor methylation, mean \pm s.d. & $\mathrm{P}$-value \\
\hline \multicolumn{4}{|l|}{ Age } \\
\hline$<60$ years & 20 & $70.8 \pm 8.3$ & NS \\
\hline$\geq 60$ years & 15 & $65.3 \pm 11.5$ & \\
\hline \multicolumn{4}{|l|}{ Gender } \\
\hline Female & 19 & $68.4 \pm 11.3$ & NS \\
\hline Male & 16 & $65.3 \pm 8.6$ & \\
\hline \multicolumn{4}{|l|}{ Site } \\
\hline Pancreatic endocrine tumors & 11 & $73.2 \pm 8.4$ & NS \\
\hline Non-ileal carcinoid tumors & 9 & $70.2 \pm 6.1$ & \\
\hline Ileal carcinoid tumors & 15 & $63.9 \pm 11.5$ & \\
\hline \multicolumn{4}{|l|}{ Size } \\
\hline$<1 \mathrm{~cm}$ & 5 & $75.6 \pm 8.8$ & 0.01 \\
\hline $1-2 \mathrm{~cm}$ & 12 & $62.6 \pm 10.6$ & \\
\hline$>2 \mathrm{~cm}$ & 18 & $70.7 \pm 7.8$ & \\
\hline \multicolumn{4}{|l|}{ Histology } \\
\hline Benign & 2 & $75.9 \pm 5.0$ & NS \\
\hline Uncertain malignant potential & 6 & $62.6 \pm 3.9$ & \\
\hline Malignant, low-grade & 27 & $67.1 \pm 10.8$ & \\
\hline \multicolumn{4}{|l|}{ Lymph node metastasis } \\
\hline Absent & 13 & $73.8 \pm 7.7$ & $0.01^{\mathrm{a}}$ \\
\hline Present & 22 & $65.3 \pm 10.0$ & \\
\hline \multicolumn{4}{|l|}{ Liver metastasis } \\
\hline Absent & 20 & $68.0 \pm 9.2$ & NS \\
\hline Present & 15 & $69.1 \pm 11.3$ & \\
\hline \multicolumn{4}{|l|}{ Chromosome $11 q$ loss } \\
\hline Absent & 28 & $67.6 \pm 10.7$ & NS \\
\hline Present & 7 & $71.8 \pm 5.8$ & \\
\hline \multicolumn{4}{|l|}{ Chromosome $16 q$ loss } \\
\hline Absent & 29 & $68.9 \pm 9.7$ & NS \\
\hline Present & 6 & $66.2 \pm 12.1$ & \\
\hline \multicolumn{4}{|l|}{ Chromosome 18 loss } \\
\hline Absent & 24 & $71.1 \pm 9.7$ & 0.02 \\
\hline Present & 11 & $62.6 \pm 8.3$ & \\
\hline \multicolumn{4}{|l|}{ p14 methylation } \\
\hline Absent & 15 & $67.8 \pm 9.1$ & NS \\
\hline Present & 20 & $69.0 \pm 10.0$ & \\
\hline \multicolumn{4}{|l|}{ p16 methylation } \\
\hline Absent & 26 & $68.4 \pm 11.0$ & NS \\
\hline Present & 9 & $68.7 \pm 6.9$ & \\
\hline \multicolumn{4}{|l|}{ MGMT methylation } \\
\hline Absent & 32 & $67.7 \pm 10.1$ & NS \\
\hline Present & 3 & $77.1 \pm 0.6$ & \\
\hline \multicolumn{4}{|l|}{ RASSF1A methylation } \\
\hline Absent & 16 & $72.6 \pm 9.7$ & 0.03 \\
\hline Present & 19 & $65.1 \pm 9.1$ & \\
\hline
\end{tabular}

${ }^{\mathrm{a}}$ RASSF1A gene methylation, lymph node metastasis and LINE tumor methylation (RASSF1A gene unmethylated, no metastasis $75.8 \pm 5.9$; unmethylated, metastasis present $67.2 \pm 12.8$; methylated, no metastasis 73.1 \pm 5.0 ; and methylated, metastasis present $64.1 \pm 9.1$; not significant).

LINE-1 and those with $<10 \%$ hypomethylation of LINE-1, including tumors with hypermethylation of LINE-1 (Table 2). In addition, tumors with $>10 \%$ hypomethylation of LINE-1 were inversely associated with $M G M T$ gene methylation $(P=0.04)$.
We have previously reported that RASSF1A gene methylation was associated with lymph node metastasis status in these tumors. ${ }^{10}$ However, no association was present among RASSF1A gene methylation, lymph node metastasis and LINE-1 
Table 2 Association of LINE-1-relative tumor hypomethylation densities and clinicopathologic features

\begin{tabular}{|c|c|c|c|c|}
\hline Clinicopathologic features (\#) & $\begin{array}{l}\text { Hypomethylation, } \\
\text { mean } \pm \text { s.d. }\end{array}$ & $\begin{array}{l}\text { P-value, } \\
\text { ANOVA }\end{array}$ & $\begin{array}{c}\text { Tumors with }>10 \% \\
\text { hypomethylation, } \% \text { (fraction) }\end{array}$ & $\begin{array}{c}\mathrm{P}-\text { value, } \\
\chi^{2}\end{array}$ \\
\hline \multicolumn{5}{|l|}{ Age } \\
\hline$<60$ years & $9.2 \pm 8.9$ & NS & $50.0(10 / 20)$ & NS \\
\hline$\geq 60$ years & $14.5 \pm 10.8$ & & $63.3(10 / 15)$ & \\
\hline \multicolumn{5}{|l|}{ Gender } \\
\hline Female & $9.4 \pm 10.3$ & NS & $47.3(9 / 19)$ & NS \\
\hline Male & $14.0 \pm 9.4$ & & $68.7(11 / 16)$ & \\
\hline \multicolumn{5}{|l|}{ Site and histology } \\
\hline Pancreatic endocrine tumors & $5.9 \pm 9.7$ & $0.047^{\mathrm{a}}$ & $27.3(3 / 11)$ & $0.048^{\mathrm{b}}$ \\
\hline Non-ileal carcinoid tumors & $11.4 \pm 4.6$ & & $66.7(6 / 9)$ & \\
\hline Ileal carcinoid tumors & $15.7 \pm 11.0$ & & $73.3(11 / 15)$ & \\
\hline \multicolumn{5}{|l|}{ Size } \\
\hline$<1 \mathrm{~cm}$ & $4.8 \pm 9.1$ & NS & $20.0(1 / 5)$ & NS \\
\hline $1-2 \mathrm{~cm}$ & $15.7 \pm 11.1$ & & $66.7(8 / 12)$ & \\
\hline$>2 \mathrm{~cm}$ & $10.5 \pm 8.6$ & & $61.1(11 / 18)$ & \\
\hline \multicolumn{5}{|l|}{ Histology } \\
\hline Benign & $6.9 \pm 3.7$ & NS & $0(0 / 2)$ & NS \\
\hline Uncertain malignant potential & $8.1 \pm 7.7$ & & $50.0(3 / 6)$ & \\
\hline Malignant, low-grade & $12.5 \pm 10.7$ & & $63.0(17 / 27)$ & \\
\hline \multicolumn{5}{|l|}{ Lymph node metastasis } \\
\hline Absent & $6.6 \pm 8.5$ & $0.02^{\mathrm{c}}$ & $33.3(4 / 12)$ & $0.04^{\mathrm{d}}$ \\
\hline Present & $14.4 \pm 9.9$ & & $69.6(16 / 23)$ & \\
\hline \multicolumn{5}{|l|}{ Liver metastasis } \\
\hline Absent & $13.4 \pm 10.4$ & NS & $60.0(12 / 20)$ & NS \\
\hline Present & $8.9 \pm 9.2$ & & $53.3(8 / 15)$ & \\
\hline \multicolumn{5}{|l|}{ Chromosome $11 q$ loss } \\
\hline Absent & $12.1 \pm 10.7$ & NS & $57.1(16 / 28)$ & NS \\
\hline Present & $9.2 \pm 6.7$ & & $57.1(4 / 7)$ & \\
\hline \multicolumn{5}{|l|}{ Chromosome $16 q$ loss } \\
\hline Absent & $11.6 \pm 10.6$ & NS & $58.6(17 / 29)$ & NS \\
\hline Present & $10.9 \pm 7.0$ & & $50.0(3 / 6)$ & \\
\hline \multicolumn{5}{|l|}{ Chromosome 18 loss } \\
\hline Absent & $7.4 \pm 8.2$ & 0.001 & $37.5(9 / 24)$ & 0.001 \\
\hline Present & $20.5 \pm 7.6$ & & $100(11 / 11)$ & \\
\hline \multicolumn{5}{|l|}{ p14 methylation } \\
\hline Absent & $11.5 \pm 6.8$ & NS & $60.0(9 / 15)$ & NS \\
\hline Present & $11.5 \pm 12.1$ & & $55.0(11 / 20)$ & \\
\hline \multicolumn{5}{|l|}{ p16 methylation } \\
\hline Absent & $11.5 \pm 10.4$ & NS & $53.8(14 / 26)$ & NS \\
\hline Present & $11.5 \pm 9.3$ & & $66.7(6 / 9)$ & \\
\hline \multicolumn{5}{|l|}{ MGMT methylation } \\
\hline Absent & $12.1 \pm 10.2$ & NS & $62.5(20 / 32)$ & 0.04 \\
\hline Present & $5.2 \pm 4.0$ & & $0(0 / 3)$ & \\
\hline \multicolumn{5}{|l|}{ RASSF1A methylation } \\
\hline Absent & $7.3 \pm 7.8$ & 0.02 & $37.5(6 / 16)$ & 0.03 \\
\hline Present & $15.0 \pm 10.5$ & & $73.7(14 / 19)$ & \\
\hline
\end{tabular}

${ }^{\mathrm{a}}$ Pancreatic endocrine tumors $6.0 \pm 9.7$ vs $14.1 \pm 9.2$ in carcinoid tumors $(P=0.02)$.

${ }^{\mathrm{b}}$ Pancreatic endocrine tumors $27.3 \%(3 / 11)$ vs $70.8(17 / 24)$ in carcinoid tumors $(P=0.02)$.

${ }^{\mathrm{c}} R A S S F 1 A$ gene methylation, lymph node metastasis and LINE-relative tumor hypomethylation ( $R A S S F 1 A$ unmethylated, no metastasis 5.2 \pm 7.8 ; unmethylated, metastasis present 10.9 \pm 6.8 ; methylated, no metastasis $6.9 \pm 10.9$; and methylated, metastasis present 15.9 \pm 10.4 ; not significant). ${ }^{\mathrm{d}}$ RASSF1A gene methylation, lymph node metastasis and $>10 \%$ LINE tumor hypomethylation (RASSF1A unmethylated, no metastasis three of 10; unmethylated, metastasis present three of six; methylated, no metastasis one of two; and methylated, metastasis present 13 of 17 , not significant). 
methylation. LINE-1 tumor methylation levels were lower, whereas LINE-1 relative tumor hypomethylation were higher and frequency of dichotomized tumors with $>10 \%$ LINE-1 hypomethylation were higher in tumors with lymph node metastasis, but were not significantly different in patients with or without RASSF1A methylation (Tables 1 and 2).

Alu methylation was lower in tumors with methylation of MGMT $(77.1 \pm 13.4)$ compared with those without MGMT methylation (85.6 \pm 4.8 , $P=0.02$ ). There was no association between Alu methylation in tumors and other clinicopathologic features.

\section{Discussion}

We studied global methylation levels in neuroendocrine tumors and found hypomethylation in LINE-1 and Alu-repetitive sequences in more than half of the tumors. Hypomethylation was more common in carcinoid tumors compared with pancreatic endocrine tumors. In addition, hypomethylation was more frequent in LINE-1 than Alu sequences. Sitespecific differences in hypomethylation of repetitive sequences have been reported for normal tissue and tumors, histological type of tumor and different types of repetitive sequences (reviewed by Hoffman and Schulz ${ }^{25}$ and Chalitchagorn et $a l^{26}$ ). For example, hypomethylation is common in colon, liver, stomach, esophagus, lung, breast, head and neck, as well as urothelial and metastatic prostate carcinomas, but uncommon in renal cell carcinomas, papillary carcinomas of thyroid, lymphomas and most hematological malignancies. ${ }^{25-29}$ This is also corroborated in experimental models of global hypomethylation in mice. The DNA methyltransferase-1 hypomorphic mice had suppression of polyp formation and reduction in the frequency of $\mathrm{CpG}$ island methylation in both the normal mucosa and adenomas in Apc $(\mathrm{Min} /+)$ mice, but developed T-cell lymphomas and liver tumors. ${ }^{30-32}$

In our current study, LINE-1 relative tumor hypomethylation was more common in patients whose tumors had loss of chromosome 18 and methylation of $R A S S F 1 A$, gene but was inversely correlated with $M G M T$ gene methylation. However, in our study, hypomethylation is not a sensitive or valuable marker of generalized $\mathrm{CpG}$ island methylation status (methylation of multiple genes). Some of these genetic and epigenetic events are dependent on the site of primary tumor. We have previously reported site-specific genetic and epigenetic alterations in these tumors, including loss of chromosome 18 in ileal carcinoid tumors ${ }^{9}$ and lack of $M G M T$ methylation in ileal carcinoid tumors. ${ }^{10}$ By contrast, in our previous study, RASFF1A gene methylation was frequently present in all sites and was associated with lymph node metastasis. ${ }^{10}$ In our present study, LINE-1 hypomethylation was associated with lymph node metastasis and was independent of
RASSF1A methylation. Previous studies have shown associations between hypomethylation and genetic or epigenetic alterations. For example, in prostatic adenocarcinomas, genome-wide DNA hypomethylation by LINE-1 was associated with alterations (either loss or gain) of chromosome $8,{ }^{33}$ and global hypomethylation in colorectal cancers was more common in microsatellite stable tumors than in microsatellite instability-high tumors. ${ }^{34}$ However, at least in some tumor sites, methylation of $\mathrm{CpG}$ islands in the promoter regions of the genes were unassociated with global hypomethylation, including colorectal neoplasms ${ }^{35}$ and stomach cancers. ${ }^{36}$ We did not have any survival difference with methylation levels of LINE-1 and Alu in these indolent tumors, but in a previous study of patients with acute lymphoblastic leukemia, LINE-1 hypomethylation and methylation of multiple CpG islands were independent prognostic factors for prognosis. ${ }^{37}$

In our study, LINE-1 and Alu methylation density in tumors and relative tumor hypomethylation levels were correlated with each other. However, most of the associations with clinicopathologic features were with LINE-1 tumor methylation and LINE-1 relative tumor hypomethylation. This suggests that there may be differences in the regulation of different types of repetitive sequences and even individual repetitive sequences in the human genome. This is corroborated by the analyses of distribution of these repetitive sequences in the human genome: LINE-1 are more frequent in GCpoor regions of the human genome and Alu are more frequent in GC-rich regions, whereas 'younger' Alus that have recently integrated and have less divergence from the consensus sequence are preferentially located in GC-poor regions. ${ }^{18,19,38}$

Is LINE-1 and Alu hypomethylation in tumors an epiphenomenon? In mammals including humans, the majority of LINE-1 are inactive, defective elements owing to $5^{\prime}$ truncation, inversion or point mutations, but 3000-5000 are full-length elements that are capable of retrotransposition. ${ }^{18,19}$ LINE-1 can be copied into RNA and reverse-transcribed, and the resulting DNA can insert into the genome at a new location. Alu are non-autonomous, but reverse transcriptase/endonuclease encoded by LINE-1 can cause Alu transposition because of similar target site duplication and insertion site specificity. Insertion of LINE-1 and Alu at a new location can disrupt genes and cause a variety of diseases (reviewed by Ostertag and Kazazian ${ }^{18}$ ). Studies of human LINE-1 retrotransposition in a tissue culture model have demonstrated genomic instability, principally in the form of substantial deletions, in about $10 \%$ of LINE-1 insertions. ${ }^{39,40}$ LINE-1 and Alu activity can cause initiation and progression of tumors.

In summary, our data demonstrated that hypomethylation is present in a subset of neuroendocrine tumors. LINE-1 hypomethylation is more common 
in carcinoid tumors than in pancreatic endocrine tumors and is associated with several clinicopathologic features, and genetic and epigenetic alterations, including lymph node metastasis.

\section{Acknowledgements}

We thank Ms Kim-Anh Vu for her assistance with the figures and Gloria Levingston for typing the paper. This study was supported by a grant to AR and JCY from Dr and Mrs Raymond R and Beverly Sackler.

\section{References}

1 Modlin IM, Lye KD, Kidd M. A 5-decade analysis of 13,715 carcinoid tumors. Cancer 2003;97:934-959.

2 Buchanan KD, Johnston CF, O'Hare MM, et al. Neuroendocrine tumors: a European view. Am J Med 1986;81:14-22.

3 Görtz B, Roth J, Krahenmann A, et al. Mutations and allelic deletions of the MEN1 gene are associated with a subset of sporadic endocrine pancreatic and neuroendocrine tumors and not restricted to foregut neoplasms. Am J Pathol 1999;154:429-436.

4 Bartsch DK, Kersting M, Wild A, et al. Low frequency of p16 (INK4a) alterations in insulinomas. Digestion 2000;62:171-177.

5 Serrano J, Goebel SU, Peghini PL, et al. Alterations in the p16INK4a/CDKN2A tumor suppressor gene in gastrinomas. J Clin Endocrinol Metab 2000;85: 4146-4156.

6 Lubomierski N, Kersting M, Bert T, et al. Tumor suppressor genes in the 9p21 gene cluster are selective targets of inactivation in neuroendocrine gastroenteropancreatic tumors. Cancer Res 2001;61:5905-5910.

7 Chan AO, Kim SG, Bedeir A, et al. CpG island methylation in carcinoid and pancreatic endocrine tumors. Oncogene 2003;22:924-934.

8 House MG, Herman JG, Guo MZ, et al. Aberrant hypermethylation of tumor suppressor genes in pancreatic endocrine neoplasms. Ann Surg 2003;238: 423-431.

9 Wang GG, Yao JC, Worah S, et al. Comparison of genetic alterations in neuroendocrine tumors: frequent loss of chromosome 18 in ileal carcinoid tumors. Mod Pathol 2005;18:1079-1087.

10 Liu L, Broaddus RR, Yao JC, et al. Epigenetic alterations in neuroendocrine tumors: methylation of RASassociation domain family 1 , isoform A and p16 genes are associated with metastasis. Mod Pathol 2005;18: 1632-1640.

11 Bird A. The essentials of DNA methylation. Cell 1992;70:5-8.

12 Jones PA, Baylin SB. The fundamental role of epigenetic events in cancer. Nat Rev Genet 2002;3:415-428.

13 Jones PA, Takai D. The role of DNA methylation in mammalian epigenetics. Science 2001;293:1068-1070.

14 Issa JA. CpG-island methylation in aging and cancer. Curr Top Microbiol Immunol 2000;249:101-118.

15 Feinberg AP, Vogelstein V. Hypomethylation distinguishes genes of some human cancers from their normal counterparts. Nature 1983;301:89-92.
16 Feinberg AP, Gehrke CW, Kuo KC, et al. Reduced genomic 5-methylcystosine content in human colonic neoplasia. Cancer Res 1998;48:1159-1161.

17 Lengauer C, Kinzler KW, Vogelstein B. DNA methylation and genetic instability in colorectal cancer cells. Proc Natl Acad Sci USA 1997;94:2103-2105.

18 Ostertag EM, Kazazian Jr HH. Biology of mammalian L1 retrotransposons. Annu Rev Genet 2001;35: 501-538.

19 Kazazian Jr HH, Goodier JL. LINE drive: retrotransposition and genomic instability. Cell 2002;110:277-280.

$20 \mathrm{Gu}$ Z, Wang H, Nekrutenko A, et al. Densities, length proportions, and other distributional features of repetitive sequences in the human genome estimated from 430 megabases of genomic sequence. Gene 2000;259: 81-88.

21 Kochanek S, Renz D, Doerfler W. DNA methylation in the Alu sequences of diploid and haploid primary human cells. EMBO J 1993;12:1141-1151.

22 Schmid CW. Does SINE evolution preclude Alu function? Nucleic Acids Res 1998;26:4541-4550.

23 Yang AS, Estecio MRH, Doshi K, et al. A simple method for estimating global DNA methylation using bisulfite PCR of repetitive DNA elements. Nucl Acids Res 2004;32:e38.

24 Kloppel G, Perren A, Heitz PU. The gastroenteropancreatic neuroendocrine cell system and its tumors: the WHO classification. Ann NY Acad Sci 2004;1014: 13-27.

25 Hoffman MJ, Schulz WA. Causes and consequences of DNA hypomethylation in human cancer. Biochem Cell Biol 2005;83:296-321.

26 Chalitchagorn K, Shuangshoti S, Hourpai N, et al. Distinctive pattern of LINE-1 methylation level in normal tissues and the association with carcinogenesis. Oncogene 2004;23:8841-8846.

27 Cravo M, Pinto R, Fidalgo P, et al. Global DNA hypomethylation occurs in the early stages of intestinal type gastric carcinoma. Gut 1996;39:434-438.

28 Florl AR, Lower R, Schmitz-Drager BJ, et al. DNA methylation and expression of LINE-1 and HERV-K provirus sequences in urothelial and renal cell carcinomas. Br J Cancer 1999;80:1312-1321.

29 Lin CH, Hsieh SY, Sheen IS, et al. Genome-wide hypomethylation in hepatocellular carcinogenesis. Cancer Res 2001;61:4238-4243.

30 Eads CA, Nickel AE, Laird PW. Complete genetic suppression of polyp formation and reduction of CpGisland hypermethylation in Apc(Min/+) Dnmt1-hypomorphic mice. Cancer Res 2002;62:1296-1299.

31 Yamada Y, Jackson-Grusby L, Linhart H, et al. Opposing effects of DN hypomethylation on intestinal and liver carcinogenesis. Proc Natl Acad Sci USA 2005; 102:13580-13585.

32 Gaudet F, Hodgson JG, Eden A, et al. Induction of tumors in mice by genomic hypomethylation. Science 2003;300:489-492.

33 Schulz WA, Elo JP, Florl AR, et al. Genomewide DNA hypomethylation is associated with alterations on chromosome 8 in prostate carcinoma. Genes Chromosomes Cancer 2002;35:58-65.

34 Matsuzaka K, Deng G, Tanaka H, et al. The relationship between global methylation level, loss of heterozygosity, and microsatellite instability in sporadic colorectal cancer. Clin Cancer Res 2005;11:8564-8569.

35 Bariol C, Suter C, Cheong K, et al. The relationship between hypomethylation and $\mathrm{CpG}$ island methylation 
in colorectal neoplasia. Am J Pathol 2003;162: 1361-1371.

36 Kaneda A, Tsukamoto $\mathrm{T}$, Takamura-Enya $\mathrm{T}$, et al. Frequent hypomethylation in multiple CpG islands is associated with globel hypomethylation, but not with frequent promoter hypermethylation. Cancer Sci 2004;95:58-64.

37 Roman-Gomez J, Jimenez-Velasco A, Agirre X, et al. Promoter hypermethylation and global hypomethylation are independent epigenetic events in lymphoid leukemogenesis with opposing effects on clinical outcome. Leukemia 2006;20: 1445-1448.

38 Pavlicek A, Jabbari K, Paces V, et al. Similar integration but different stability of Alus and LINEs in the human genome. Gene 2001;276:39-45.

39 Gilbert N, Lutz-Prigge S, Moran J. Genomic deletions created upon LINE-retrotransposition. Cell 2002;110: 315-325.

40 Symer DE, Connelly C, Szak ST, et al. Human L1 retrotransposition is associated with genetic instability in vivo. Cell 2002;110:327-338. 